\title{
Tumor suppressive microRNA-218 inhibits cancer cell migration and invasion by targeting focal adhesion pathways in cervical squamous cell carcinoma
}

\author{
NORIKO YAMAMOTO $^{1,2}$, TAKASHI KINOSHITA ${ }^{1}$, NIJIRO NOHATA ${ }^{1}$, \\ TOSHIHIKO ITESAKO ${ }^{3}$, HIROFUMI YOSHINO ${ }^{3}$, HIDEKI ENOKIDA ${ }^{3}$, \\ MASAYUKI NAKAGAWA ${ }^{3}$, MAKIO SHOZU ${ }^{2}$ and NAOHIKO SEKI ${ }^{1}$

\begin{abstract}
Departments of ${ }^{1}$ Functional Genomics and ${ }^{2}$ Obstetrics and Gynecology Medicine, Chiba University Graduate School of Medicine, Chiba; ${ }^{3}$ Department of Urology, Graduate School of Medical and Dental Sciences, Kagoshima University, Kagoshima, Japan
\end{abstract}

Received December 20, 2012; Accepted February 8, 2013

DOI: 10.3892/ijo.2013.1851

\begin{abstract}
Cervical cancer is one of the most common cancers in women. More than 275,100 women die from cervical cancer each year. Cervical squamous cell carcinoma (cervical SCC), one of the most frequent types of cervical cancers, is associated with high-risk human papilloma virus (HPV), although HPV infection alone may not be enough to induce malignant transformation. MicroRNAs (miRNAs), a class of small non-coding RNAs, regulate protein-coding gene expression by repressing translation or cleaving RNA transcripts in a sequence-specific manner. A growing body of evidence suggests that miRNAs contribute to cervical SCC progression, development and metastasis. miRNA expression signatures in SCC (hypopharyngeal SCC and esophageal SCC) revealed that $m i R-218$ expression was significantly reduced in cancer tissues compared with adjacent noncancerous epithelium, suggesting that $m i R-218$ is a candidate tumor suppressor. The aim of this study was to investigate the functional significance of $m i R-218$ in cervical SCC and to identify novel $m i R-218$-mediated cancer pathways in cervical SCC. Restoration of $m i R-218$ significantly inhibited cancer cell migration and invasion in both HPV-positive and HPV-negative cervical SCC cell lines. These data indicated that $m i R-218$ acts as a tumor suppressor in cervical SCC. Our in silico analysis showed that $m i R-218$ appeared to be an important modulator of tumor cell processes through suppression of many targets, particularly those involved in focal adhesion signaling pathways. Gene expression data
\end{abstract}

Correspondence to: Dr Naohiko Seki, Department of Functional Genomics, Chiba University Graduate School of Medicine, 1-8-1 Inohana Chuo-ku, Chiba 260-8670, Japan

E-mail: naoseki@faculty.chiba-u.jp

Key words: microRNA, miR-218, tumor suppressor, cervical cancer, LAMB3, focal adhesion indicated that $L A M B 3$, a laminin protein known to influence cell differentiation, migration, adhesion, proliferation and survival, was upregulated in cervical SCC clinical specimens, and silencing studies demonstrated that $L A M B 3$ functioned as an oncogene in cervical SCC. The identification of novel tumor-suppressive miR-218-mediated molecular pathways has provided new insights into cervical SCC oncogenesis and metastasis.

\section{Introduction}

Cervical cancer is one of the most common cancers in women. It has been estimated that more than 529,800 new cases will be diagnosed each year, and approximately 275,100 women worldwide will die of cervical cancer each year (1). Cervical squamous cell carcinoma (cervical SCC) is one of the most frequent types of cervical cancers, accounting for $80-90 \%$ of cervical cancers, and the most important risk factor for cervical SCC is persistent human papilloma virus (HPV) infection (2). Epidemiological studies have indicated that more than $99 \%$ of patients with cervical SCC are positive for high-risk HPV (HPV16, HPV18 and HPV31) $(3,4)$. The high-risk HPVs contain oncoproteins, i.e., E6 and E7, which contribute to oncogenesis of cervical SCC by silencing the tumor-suppressive $\mathrm{p} 53$ and $\mathrm{Rb}$ proteins (5-8). The molecular mechanisms of cervical SCC initiation, development and metastasis have not yet been fully elucidated. Therefore, an increased understanding of the molecular targets and pathways of cervical SCC progression and metastasis is necessary, preferably using latest approaches in genomic analysis, including non-coding RNA studies.

RNA can be divided into 2 categories: protein-coding RNA and non-coding RNA (ncRNA). It is important to examine the functions of ncRNAs and their association with human disease, including cancer. MicroR NAs (miRNAs) are endogenous small ncRNA molecules (19-22 bases in length) that regulate protein-coding gene expression by repressing translation or cleaving RNA transcripts in a 
sequence-specific manner (9). A growing body of evidence suggests that miRNAs are aberrantly expressed in many human cancers and that they play significant roles in the initiation, development and metastasis of these cancers (10). Some highly expressed miRNAs can function as oncogenes by repressing tumor suppressors, whereas low-level miRNAs can function as tumor suppressors by negatively regulating oncogenes (11).

We previously performed miRNA expression signature analysis of hypopharyngeal, maxillary sinus, esophageal and lung SCCs, in addition to bladder cancer and renal cell carcinoma; these studies indicated that $m i R$ - 218 was significantly reduced in cancer tissues compared with adjacent non-cancerous tissues, suggesting that $m i R-218$ is a candidate tumor-suppressive miRNA in human cancers (12-18). The results of past functional studies of $m i R-218$ in various cancers indicated that $m i R-218$ inhibits cancer cell proliferation and invasion through targeting oncogenic genes (19-23). Interestingly, $m i R$ - 218 was underexpressed in HPV-positive cell lines, cervical lesions, and cancer tissues containing HPV16 DNA, as compared to both C-33A cells and normal cervical tissues (24).

The aim of the study was to investigate the functional significance of $m i R-218$ in both HPV-positive and -negative cell lines and to identify the molecular pathways mediating $m i R-218$ in cervical SCC cells. Genome-wide gene expression data for $m i R-218$ and in silico database analyses showed that the focal adhesion pathway was a promising $m i R-218$ target pathway. The laminins $L A M B 3$ and $L A M C 1$ are an important and biologically active part of the basal lamina, influencing cell differentiation, migration, adhesion, proliferation and survival. In this study, we focused on $L A M B 3$ and investigation of the functional significance of this gene in cervical SCC. The novel tumor-suppressive $m i R$-218-mediated cancer pathways identified herein provide new insights into the potential mechanisms of cervical SCC oncogenesis and metastasis.

\section{Materials and methods}

Clinical specimens. A total of 18 primary cervical SCC specimens and 11 non-cancerous specimens were collected from patients who had undergone surgical treatment at Chiba University Hospital. The samples were processed and stored in RNAlater (Qiagen, Valencia, CA, USA) at $-20^{\circ} \mathrm{C}$ until RNA extraction. Patient information is summarized in Table I. Our study was approved by the Bioethics Committee of Chiba University; prior written informed consent and approval was given by each patient.

Cervical SCC cell lines. CaSki (HPV16-positive) and ME180 (HPV39-positive) cells were grown in RPMI-1640 medium supplemented with $10 \%$ fetal bovine serum. HeLa (HPV18-positive) cells were grown in E-MEM medium supplemented with $10 \%$ fetal calf serum, and Yumoto (HPV-negative) cells were grown in E-MEM medium supplemented with $10 \%$ fetal bovine serum. All cells were cultured in a humidified atmosphere containing $5 \% \mathrm{CO}_{2}$ at $37^{\circ} \mathrm{C}$.

RNA isolation. Total RNA was isolated using TRIzol Reagent (Invitrogen, Carlsbad, CA, USA) according to the
Table I. Characteristics of cervical-SCC specimens and non-cancerous specimens.

\begin{tabular}{|c|c|c|c|c|c|}
\hline No. & Age & $\begin{array}{l}\text { FIGO } \\
\text { stage }\end{array}$ & $\begin{array}{c}\text { Tumor } \\
\text { size }(\mathrm{cm})\end{array}$ & $\begin{array}{l}\text { Lymph node } \\
\text { metastasis }\end{array}$ & $\begin{array}{l}\text { HPV } \\
\text { status }\end{array}$ \\
\hline 1 & 58 & IIB & $1.7 \times 1.9$ & - & 16 \\
\hline 2 & 64 & IIB & ND & - & 16 \\
\hline 3 & 37 & IIB & $3.5 \times 3.0$ & + & 16 \\
\hline 4 & 41 & IB2 & $8.3 \times 3.3$ & - & 16 \\
\hline 5 & 39 & IB 1 & $3.5 \times 3.4$ & - & 16 \\
\hline 6 & 34 & IB1 & $3.2 \times 2.2$ & - & 16 \\
\hline 7 & 43 & IB2 & $4.0 \times 8.0$ & - & 18 \\
\hline 8 & 56 & IIIB & $3.0 \times 3.1$ & + & 16,18 \\
\hline 9 & 77 & IIB & $3.0 \times 2.7$ & - & 16 \\
\hline 10 & 62 & IB1 & $3.0 \times 2.0$ & - & 16 \\
\hline 11 & 56 & IIIA & $4.5 \times 2.2$ & + & 16 \\
\hline 12 & 56 & IIA & $4.0 \times 4.0$ & - & 16 \\
\hline 13 & 60 & IB1 & $4.0 \times 4.0$ & - & 16 \\
\hline 14 & 32 & IIB & $6.0 \times 3.0$ & + & 16 \\
\hline 15 & 38 & IB2 & $6.8 \times 4.6$ & + & 16 \\
\hline 16 & 44 & IB1 & $3.5 \times 2.2$ & - & 16 \\
\hline 17 & 40 & IB1 & $3.0 \times 2.0$ & - & 16 \\
\hline 18 & 63 & IB1 & $2.7 \times 2.4$ & - & 16 \\
\hline
\end{tabular}

\begin{tabular}{rrr}
\hline & & $\begin{array}{c}\text { HPV } \\
\text { status }\end{array}$ \\
\hline 1 & 44 & - \\
2 & 77 & - \\
3 & 75 & - \\
4 & 45 & - \\
5 & 47 & - \\
6 & 69 & - \\
7 & 40 & - \\
8 & 48 & - \\
9 & 41 & - \\
10 & 41 & - \\
11 & 34 & - \\
\hline
\end{tabular}

ND, no data.

manufacturer's protocol. RNA concentration was determined spectrophotometrically. RNA quality was confirmed using a NanoDrop 1000 Spectrophotometer (Thermo Fisher Scientific, Wilmington, DE, USA).

DNA isolation and HPV status. Genomic DNA was extracted by QIAamp DNA mini kit (Qiagen, Venlo, The Netherlands). Samples without HPV infection were determined by PCR amplification using the L1 consensus primers MY09 and MY11 as described previously (25). HPV-positive samples were analyzed to determine the presence of DNA for HPV16 and HPV18. We designed type-specific real-time PCR primers for the E6 and E7 regions of HPV16 and HPV18 (Table II), 
Table II. Primer sequences of HPV detection.

\begin{tabular}{llrr}
\hline Primer & \multicolumn{1}{c}{ Sequence (5' to 3') } & Location & Product size (bp) \\
\hline HPV 16 E6-F & GCACCAAAAGAGAACTGCAATGTT & $85-108$ \\
HPV 16 E6-R & AGTCATATACCTCACGTCGCAGTA & $203-226$ \\
HPV 16 E7-F & CAAGTGTGACTCTACGCTTCGG & $738-759$ \\
HPV 16 E7-R & GTGCCCATTAACAGGTCTTCCAA & $796-818$ \\
HPV 18 E6-F & CTATAGAGGCCAGTGCCATTCG & $503-524$ \\
HPV 18 E6-R & TTATACTTGTGTTTCTCTGCGTCG & $558-581$ \\
HPV 18 E7-F & TAATCATCAACATTTACCAGCCCG & $721-744$ \\
HPV 18 E7-R & CGTCTGCTGAGCTTTCTACTACTA & $810-833$ \\
\hline
\end{tabular}

and real-time PCR was performed using a LightCyclerNano PCR System according to the manufacturer's protocol.

Quantitative real-time RT-PCR. Stem-loop RT-PCR (TaqMan MicroRNA assays; P/N: 000521 for $m i R-218$; Applied Biosystems, Foster City, CA, USA) was used to quantify miRNAs according to earlier published conditions (13). To normalize the data for quantification of $m i R-218$, we used RNU48 (assay ID: 001006; Applied Biosystems). TaqMan probes and primers for LAMB3 (P/N: Hs00165078_m1) and GAPDH (P/N: Hs02758991_g1) were obtained from Applied Biosystems. Primers for ACTB (P/N: ACTB 533F 37546-020, ACTB 653R 37546-021) were obtained from Sigma genetics. We used the $\Delta \Delta \mathrm{Ct}$ method to calculate the fold-change.

Mature miRNA and siRNA transfections. Cervical SCC cell lines were transfected with Lipofectamine RNAiMAX transfection reagent (Invitrogen) and Opti-MEM (Invitrogen) with $10 \mathrm{nM}$ mature miRNA or siRNA molecules. The following RNA species were used in this study: mature miRNA, Pre-miR miRNA Precursor (hsa-miR-218; Applied Biosystems, P/N: AM17100), negative control miRNA (Applied Biosystems, P/N: AM17111), small-interfering RNA (Silencer Select, Applied Biosystems, si-LAMB3, P/N: s8075 and s8076), and negative control siRNA (Stealth RNAi Negative Control Medium GC Duplex, Invitrogen, P/N: 12935-300). Cells were seeded in $10-\mathrm{cm}$ dishes for protein extraction $\left(8 \times 10^{5}\right.$ cells per dish), 24-well plates for mRNA extraction and Matrigel invasion assays $\left(5 \times 10^{4}\right.$ cells per well), and 96 -well plates for XTT assays (ME180: 3,000 cells per well; CaSki and HeLa: 4,000 cells per well; and Yumoto: $2 \times 10^{4}$ cells per well).

Cell proliferation, migration, and invasion assays. Cell proliferation was determined using an XTT assay (Roche Applied Science, Tokyo, Japan) according to the manufacturer's instructions. Cell migration assays were performed using modified Boyden Chambers (Transwells, Costar \#3422, Corning Incorporated, Corning, NY, USA) containing uncoated Transwell polycarbonate membrane filters with $8-\mu \mathrm{m}$ pores in 24-well tissue culture plates. Cells were transfected with $10 \mathrm{nM}$ miRNA by reverse transfection and plated in $10-\mathrm{cm}$ dishes at $8 \times 10^{5}$ cells. After $48 \mathrm{~h}, 1 \times 10^{5}$ cells were added to the upper chamber of each migration well and were allowed to migrate for $48 \mathrm{~h}$. After gentle removal of the non-migratory cells from the filter surface of the upper chamber, the cells that migrated to the lower side were fixed and stained with Diff-Quick (Sysmex Corporation, Kobe, Japan). The number of cells migrating to the lower surface was determined microscopically by counting 4 areas of constant size per well. A cell invasion assay was carried out using modified Boyden chambers containing transwell-precoated Matrigel membrane filter inserts with $8-\mu \mathrm{m}$ pores in 24-well tissue culture plates at $1 \times 10^{5}$ cells per well (BD Biosciences, USA). All experiments were performed in duplicate.

Pathway analysis and expression data of putative miR-218 target genes. To obtain putative $m i R-218$ regulated genes, we adopted a TargetScan database searching method (http://www. targetscan.org). To identify molecular targets and signaling pathways regulated by $m i R-218$, in silico and gene expression data were analyzed in the Kyoto Encyclopedia of Genes and Genomics (KEGG) pathway (http://www.genome.jp/kegg/ pathway.html) categories using the GeneCodis program (http://genecodis.cnb.csic.es/). In this study, we focused on the focal adhesion pathway, which included 48 genes. Gene expression data were applied using the GEO database (accession no. GSE6791).

Western blot analysis. Cells were harvested and lysed $72 \mathrm{~h}$ after transfection. Each cell lysate (50 $\mu \mathrm{g}$ of protein) was separated using Mini-PROTEAN TGX gels (Bio-Rad, Hercules, CA, USA), followed by subsequent transfer to PVDF membranes. Immunoblot analysis was performed with polyclonal anti-LAMB3 antibodies (HPA008069; SigmaAldrich, St. Louis, MO, USA). Anti-GAPDH antibodies (ab8245; Abcam, Cambridge, UK) were used as an internal control. The membrane was washed and incubated with antirabbit IgG, HRP-linked antibodies (\#7074; Cell Signaling Technology, USA). Complexes were visualized with an Immun-Star ${ }^{\mathrm{TM}}$ WesternC Chemiluminescence Kit (Bio-Rad), and the expression levels of these proteins were evaluated by ImageJ software (ver.1.44; http://rsbweb.nih.gov/ij/index.html).

Plasmid construction and dual-luciferase reporter assays. Partial sequences of the LAMB3 3' untranslated region (3'UTR) that contain the $m i R-218$ target site (ggcatgccattgaaactaagagctc tcaagtcaaggaagctgggctgggcagtatccccgcctttagttctccactggggag gaatcctggaccaagcacaaaaacttaacaaaagtgatgtaaaatgaaaagccaa 


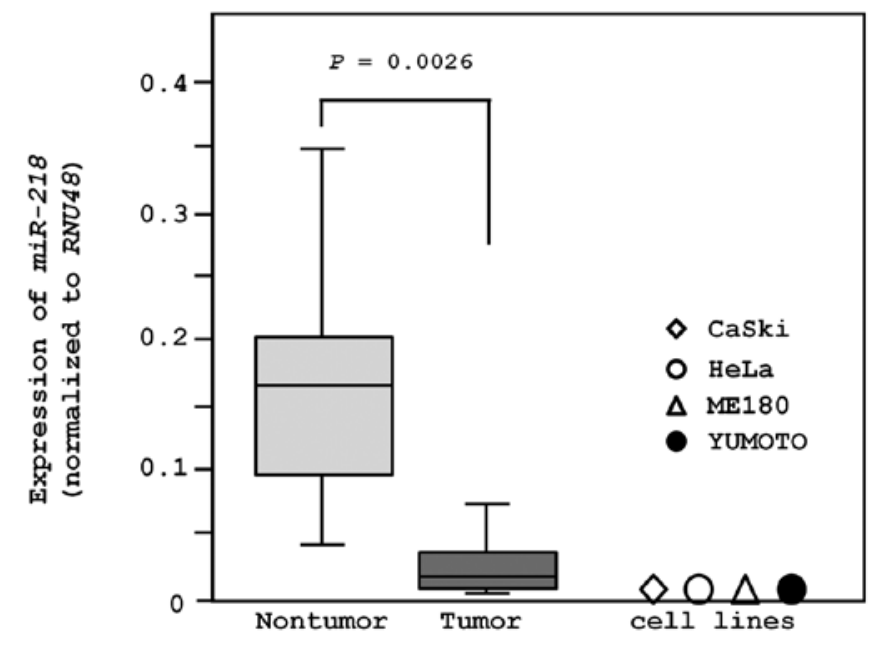

Figure 1. Expression of $m i R-218$ in cervical-SCC clinical specimens and cell lines. Expression of $m i R-218$ in cervical-SCC tumor tissues, nontumor tissues, and cell lines as determined by qRT-PCR. RNU48 was used as an internal control.

ataaaatctttggaaaagagcctggaggttc) were inserted between the XhoI and PmeI restriction sites in the 3'UTR of the hRluc gene in the psiCHECK-2 vector (Promega, Madison, WI, USA). CaSki was then transfected with $5 \mathrm{ng}$ vector, $10 \mathrm{nM}$ mature miRNA. Firefly and Renilla luciferase activities in cell lysates were determined using a dual-luciferase assay system (E1910; Promega). Normalized data were calculated as the quotient of Renilla/firefly luciferase activities.

Statistical analysis. The relationships between 2 variables and numerical values were analyzed using the Mann-Whitney
$\mathrm{U}$ test, and the relationships between 3 variables and the numerical values were analyzed using the Bonferroni-adjusted Mann-Whitney U test. Expert Stat View analysis software (ver. 4; SAS Institute Inc., Cary, NC, USA) was used in both analyses. In the comparison of 3 variables, a non-adjusted statistical level of significance of $\mathrm{P}<0.05$ corresponded to the Bonferroni-adjusted level of $\mathrm{P}<0.0167$.

\section{Results}

Expression levels of miR-218 in cervical SCC clinical specimens and cell lines. The expression of $m i R$ - 218 was significantly lower in clinical cervical SCC specimens $(n=18 ; 0.043 \pm 0.077)$ than in non-cancerous specimens $(n=11 ; 0.153 \pm 0.110$, $\mathrm{P}=0.0026$; Fig. 1). We also evaluated the expression of $m i R-218$ in cervical cancer cell lines. $m i R-218$ expression levels in CaSki (HPV16-positive), ME180 (HPV39-positive), HeLa (HPV18positive), and Yumoto (HPV-negative) were significantly lower than that in non-cancerous cervical epithelium $(\mathrm{P}<0.0001$; Fig. 1).

Effects of miR-218 restoration on cell proliferation, migration and invasion in cervical SCC cell lines. To investigate the functional role of $m i R-218$, we performed gain-of-function studies using cells transfected with a precursor of $m i R-218$. The XTT assay revealed that cell proliferation was significantly inhibited in $m i R-218$ transfectants in comparison with non-transfectants (mock) and miRNA-control transfectants (control) in ME180 cells $(78.1 \pm 3.7 \%, 100.0 \pm 2.5 \%$ and $96.0 \pm 3.5 \%$, respectively; $\mathrm{P}<0.0001)$, while no significant inhibition was seen in CaSki cells $(94.8 \pm 3.5 \%, 100.0 \pm 2.3 \%$ and $97.9 \pm 2.1 \%$, respectively; $\mathrm{P}>0.0167)$, HeLa cells $(93.0 \pm 5.0 \%, 100.0 \pm 7.5 \%$ and $97.6 \pm 4.1 \%$, respectively; $\mathrm{P}>0.0167)$, and Yumoto cells $(106.3 \pm 11.1 \%$, $100.0 \pm 3.6 \%$ and $110.8 \pm 11.8 \%$; P>0.0167; Fig. 2A).
A
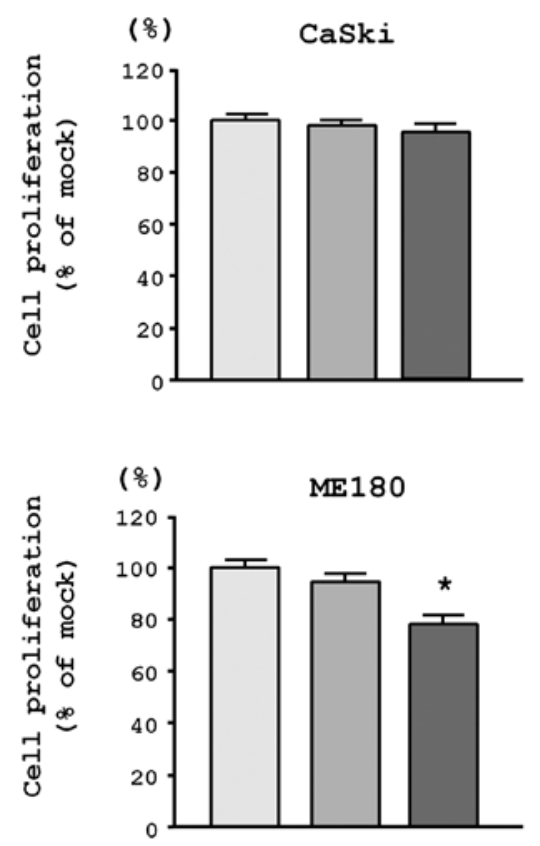
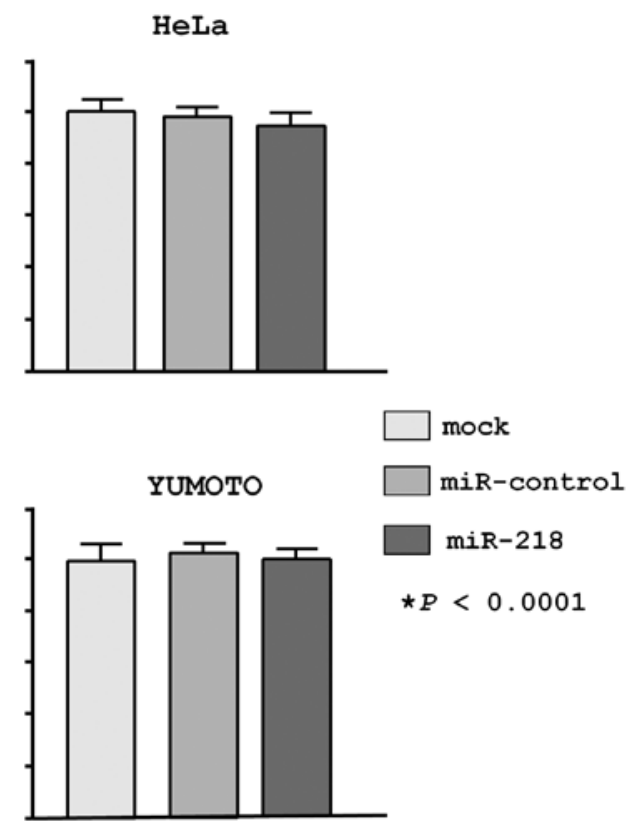

Figure 2. (A) Effects of $m i R-218$ restoration on proliferation of cervical-SCC cell lines. Proliferation activities of cervical-SCC cell lines (CaSki, ME180, HeLa and Yumoto) after transfection $(72 \mathrm{~h})$ with $m i R-218(10 \mathrm{nM})$ as determined by XTT assay. ${ }^{*} \mathrm{P}<0.0001$. 
B
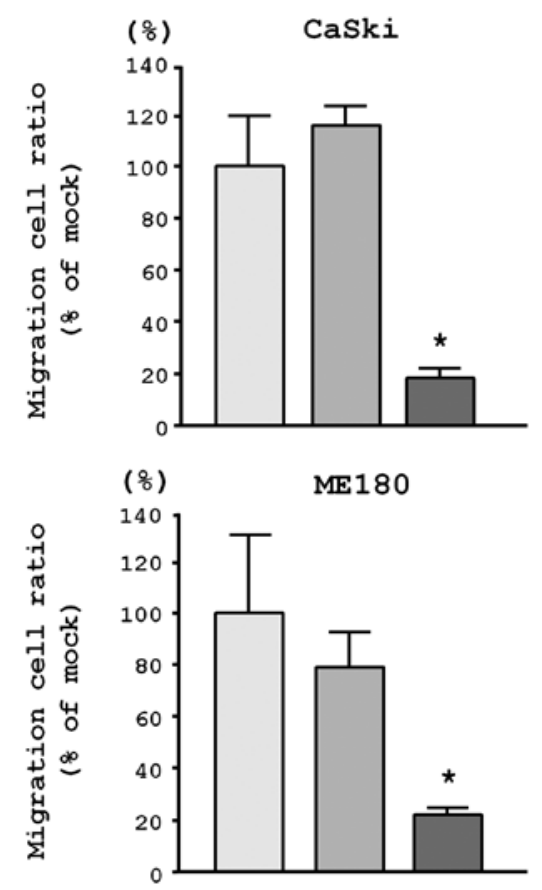

C
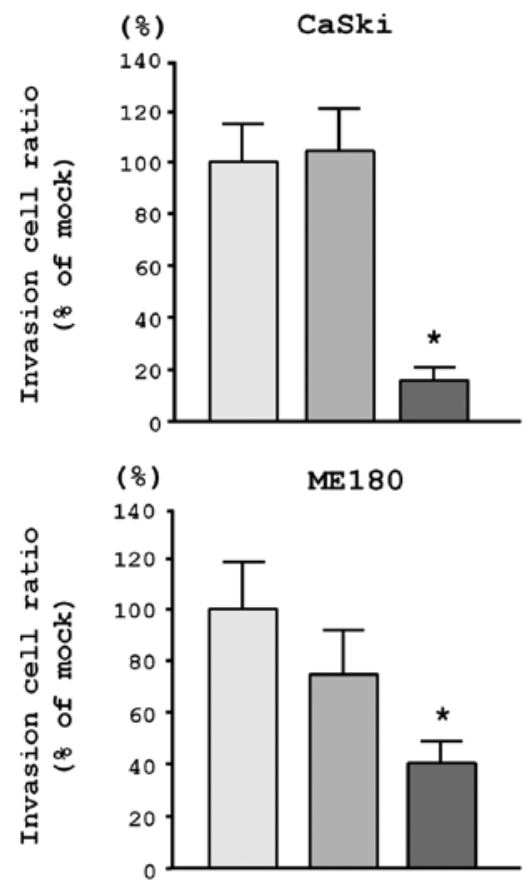
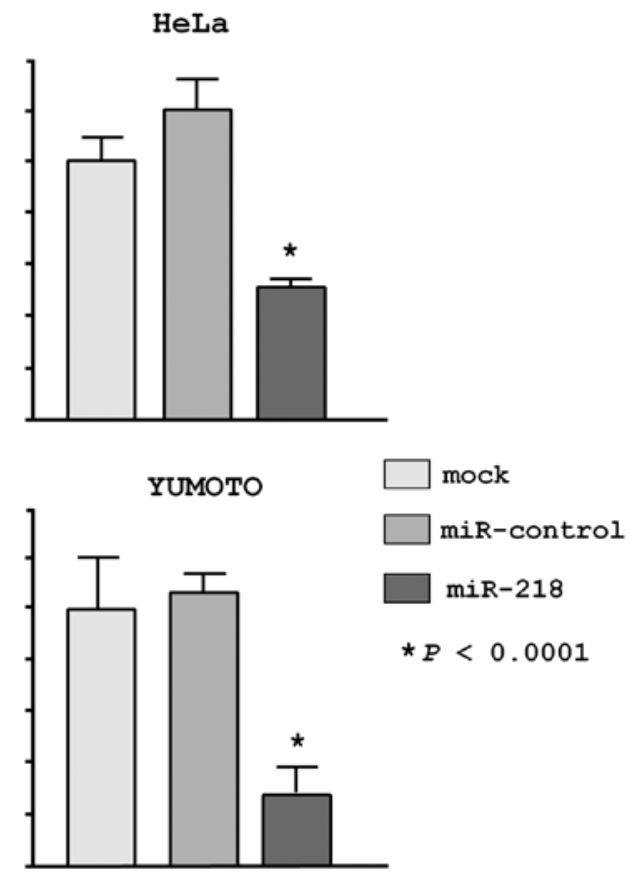

HeLa
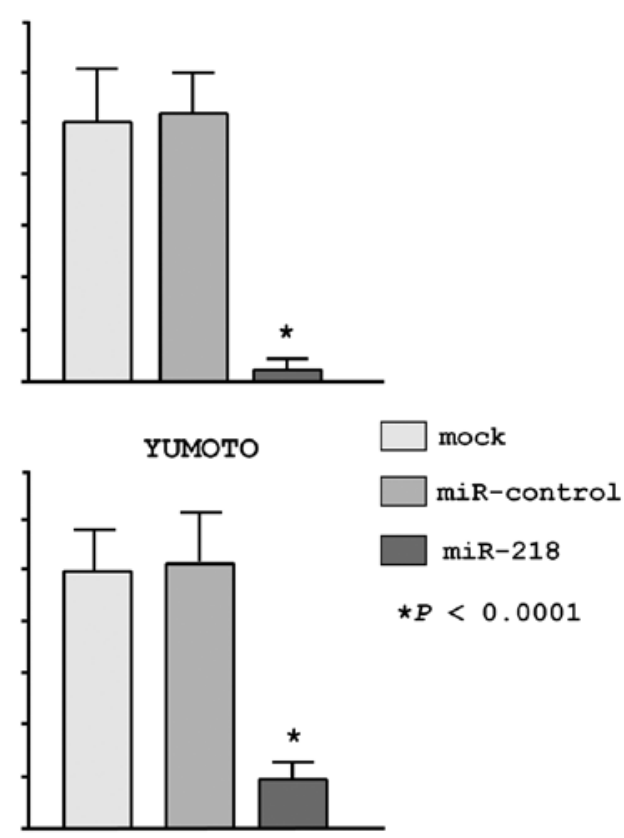

Figure 2. Continued. (B) Effects of $m i R-218$ restoration on migration of cervical-SCC cell lines. Migration activities of cervical-SCC cell lines (CaSki, ME180, HeLa and Yumoto) after transfection $(48 \mathrm{~h})$ with $m i R-218(10 \mathrm{nM})$ as determined by migration assay. *P<0.0001. (C) Effects of miR-218 restoration on invasion of cervical-SCC cell lines. Invasion activities of cervical-SCC cell lines (CaSki, ME180, HeLa and Yumoto) after transfection (48 h) with miR-218 (10 nM) as determined by Matrigel invasion assay. ${ }^{*} \mathrm{P}<0.0001$.

Migration and Matrigel invasion assays demonstrated that the number of invading cells significantly decreased in $m i R-218$ transfectants in comparison with mock and miR-control transfectants in all cell lines tested. In fact, migration in $m i R-218$ transfectants was reduced to only $11.5 \pm 3.4 \%$ in CaSki cells (mock, 100.0 \pm 20.8 ; control, 115.4 $\pm 12.2 ; \mathrm{P}<0.0001$ ), 20.3 $\pm 3.8 \%$ in ME180 cells (mock, $100.0 \pm 28.1 \%$; control, $77.2 \pm 13.8 \%$; $\mathrm{P}<0.0001$ ) 49.0 $\pm 5.9 \%$ in HeLa cells (mock, $100.0 \pm 6.8 \%$; control,
$114.1 \pm 16.8 \% ; \mathrm{P}<0.0001$ ), and $24.9 \pm 8.8 \%$ in Yumoto cells (mock,

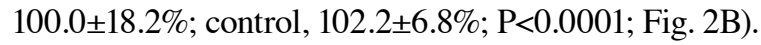

Similarly, in the Matrigel invasion assay, the number of invading cells was significantly decreased in $m i R$-218-transfectants in comparison with mock and miR-control transfectants in all cell lines. Cell invasion was reduced to $3.9 \pm 1.6 \%$

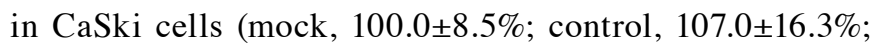
$\mathrm{P}<0.0001$ ), $37.1 \pm 9.2 \%$ in ME180 cells (mock, $100.0 \pm 14.8 \%$; 
Table III. Significantly enriched annotations regulated by $m i R-218$ (top 20 pathways).

\begin{tabular}{|c|c|c|}
\hline $\begin{array}{l}\text { No. of } \\
\text { genes }\end{array}$ & P-value & Annotations \\
\hline 59 & $1.55 \mathrm{E}-16$ & Endocytosis \\
\hline 40 & $4.29 \mathrm{E}-12$ & Glutamatergic synapse \\
\hline 69 & 4.30E-11 & Pathways in cancer \\
\hline 58 & $4.21 \mathrm{E}-10$ & MAPK signaling pathway \\
\hline 38 & $4.87 \mathrm{E}-10$ & Insulin signaling pathway \\
\hline 48 & $4.98 \mathrm{E}-10$ & Focal adhesion \\
\hline 29 & $1.53 \mathrm{E}-09$ & ErbB signaling pathway \\
\hline 25 & 3.70E-09 & Long-term depression \\
\hline 35 & $6.58 \mathrm{E}-09$ & Axon guidance \\
\hline 43 & $1.99 \mathrm{E}-08$ & Chemokine signaling pathway \\
\hline 24 & $6.10 \mathrm{E}-08$ & Chronic myeloid leukemia \\
\hline 23 & $6.35 \mathrm{E}-08$ & Long-term potentiation \\
\hline 36 & $1.00 \mathrm{E}-07$ & Wnt signaling pathway \\
\hline 33 & $1.06 \mathrm{E}-07$ & Tight junction \\
\hline 26 & $1.21 \mathrm{E}-07$ & Prostate cancer \\
\hline 26 & $1.21 \mathrm{E}-07$ & Gap junction \\
\hline 21 & $2.87 \mathrm{E}-07$ & Glioma \\
\hline 26 & 2.98E-07 & Fc $\gamma \mathrm{R}$-mediated phagocytosis \\
\hline 22 & 5.37E-07 & Adherens junction \\
\hline 38 & $5.54 \mathrm{E}-07$ & Calcium signaling pathway \\
\hline
\end{tabular}

control, 71.9 $\pm 18.1 \%$; $\mathrm{P}<0.0001$ ), $2.7 \pm 1.5 \%$ in HeLa cells (mock, $100.0 \pm 21.6 \%$; control, $102.7 \pm 19.0 \% ; \mathrm{P}<0.0001)$, and $14.9 \pm 6.6 \%$ for Yumoto cells (mock, 100.0 $\pm 14.8 \%$; control, $103.4 \pm 19.4 \%$; $\mathrm{P}<0.0001$; Fig. 2C).

Identification of miR-218-mediated molecular pathways and putative miR-218 target genes. We first obtained putative $m i R-218$ target genes by searching the TargetScan database. According to the database, 4,946 conserved targets, with a total of 1,865 conserved sites and 4,372 poorly conserved sites, were deposited in this database. These genes were analyzed and characterized in KEGG pathway categories using the GeneCodis program. This analysis revealed 105 signaling pathways (Table III). In these pathways, we focused on the focal adhesion pathway and the 48 genes contained within this pathway (Table IV). To search for genes regulated by tumor-suppressive $m i R-218$ in cervical SCC, we applied gene expression profiles in the GEO database (accession no. GSE6791). Among 48 genes, 24 genes were upregulated in cervical SCC compared to adjacent non-cancerous tissues. The expression levels of up- or downregulated genes in clinical specimens are shown in Table IV. As a result of our expression data, we identified $L A M B 3$ as one of the most highly upregulated genes in clinical specimens; this gene has 1 putative $m i R-218$ binding site. $L A M B 3$ is a laminin that is an important and biologically active part of the basal lamina, functioning in a variety of pathways, such as cell differentiation, migration, adhesion, proliferation and survival. Thus, we focused on $L A M B 3$ as a promising target gene of $m i R-218$ in cervical SCC.
Table IV. Expression of target genes by $m i R-218$ involved in focal adhesion pathways.

\begin{tabular}{|c|c|c|c|c|}
\hline $\begin{array}{l}\text { Entrez } \\
\text { gene }\end{array}$ & $\begin{array}{c}\text { Gene } \\
\text { symbol }\end{array}$ & $\mathrm{FC}$ & Regulation & P-value \\
\hline 3265 & HRAS & 4.54 & Up & 4.19E-02 \\
\hline 3914 & LAMB3 & 3.54 & Up & $4.40 \mathrm{E}-03$ \\
\hline 3676 & ITGA4 & 3.21 & Up & $6.03 \mathrm{E}-03$ \\
\hline 5062 & PAK2 & 2.40 & Up & 7.29E-05 \\
\hline 1282 & COL4A1 & 2.33 & Up & $2.21 \mathrm{E}-02$ \\
\hline 6464 & SHC1 & 2.15 & Up & $3.05 \mathrm{E}-04$ \\
\hline 87 & ACTN1 & 2.14 & Up & $3.18 \mathrm{E}-03$ \\
\hline 1399 & CRKL & 2.10 & Up & $4.50 \mathrm{E}-04$ \\
\hline 2932 & GSK3B & 1.83 & Up & $1.36 \mathrm{E}-03$ \\
\hline 394 & ARHGAP5 & 1.75 & Up & $9.48 \mathrm{E}-04$ \\
\hline 3915 & LAMC1 & 1.75 & Up & $8.18 \mathrm{E}-03$ \\
\hline 3371 & $\mathrm{TNC}$ & 1.51 & Up & 3.09E-01 \\
\hline 5501 & PPP1CC & 1.50 & Up & $6.03 \mathrm{E}-03$ \\
\hline 387 & RHOA & 1.45 & Up & 2.04E-01 \\
\hline 1301 & COL11A1 & 1.44 & Up & 3.87E-01 \\
\hline 5829 & PXN & 1.33 & Up & $1.27 \mathrm{E}-01$ \\
\hline 858 & CAV2 & 1.27 & Up & 3.09E-01 \\
\hline 3480 & IGF1R & 1.26 & Up & $2.42 \mathrm{E}-01$ \\
\hline 100291393 & LOC 100291393 & 1.09 & Up & 8.39E-01 \\
\hline 25759 & LOC 100291393 & 1.09 & Up & 8.39E-01 \\
\hline 2321 & FLT1 & 1.05 & Up & 7.22E-01 \\
\hline 5601 & MAPK9 & 1.03 & Up & 8.39E-01 \\
\hline 896 & CCND3 & 1.02 & Up & 8.79E-01 \\
\hline 5293 & PIK3CD & 1.02 & Up & 8.39E-01 \\
\hline 3691 & ITGB4 & -1.02 & Down & $9.59 \mathrm{E}-01$ \\
\hline 5500 & PPP1CB & -1.07 & Down & 4.76E-01 \\
\hline 63923 & $\mathrm{TNN}$ & -1.17 & Down & $4.46 \mathrm{E}-01$ \\
\hline 1289 & COL5A1 & -1.17 & Down & $6.84 \mathrm{E}-01$ \\
\hline 5170 & PDPK1 & -1.19 & Down & $7.51 \mathrm{E}-02$ \\
\hline 5058 & PAK1 & -1.23 & Down & $1.40 \mathrm{E}-01$ \\
\hline 7057 & THBS1 & -1.23 & Down & 4.46E-01 \\
\hline 10451 & VAV3 & -1.23 & Down & $7.60 \mathrm{E}-01$ \\
\hline 5156 & PDGFRA & -1.41 & Down & $2.63 \mathrm{E}-01$ \\
\hline 10000 & AKT3 & -1.46 & Down & $6.71 \mathrm{E}-02$ \\
\hline 1956 & EGFR & -1.51 & Down & $5.99 \mathrm{E}-02$ \\
\hline 399694 & SHC4 & -1.57 & Down & $9.33 \mathrm{E}-02$ \\
\hline 55742 & PARVA & -1.58 & Down & $1.68 \mathrm{E}-02$ \\
\hline 5579 & PRKCB & -1.71 & Down & $9.50 \mathrm{E}-03$ \\
\hline 53358 & SHC3 & -1.80 & Down & $5.33 \mathrm{E}-02$ \\
\hline 5649 & RELN & -1.81 & Down & $2.52 \mathrm{E}-02$ \\
\hline 2318 & FLNC & -1.81 & Down & $2.21 \mathrm{E}-02$ \\
\hline 5295 & PIK3R1 & -1.88 & Down & 4.19E-02 \\
\hline 1277 & COL1A1 & -2.38 & Down & 8.38E-02 \\
\hline 8515 & ITGA10 & -2.61 & Down & $9.01 \mathrm{E}-05$ \\
\hline 6714 & SRC & -2.85 & Down & $1.36 \mathrm{E}-03$ \\
\hline 81 & ACTN4 & -2.86 & Down & $3.05 \mathrm{E}-04$ \\
\hline 3479 & IGF1 & -2.97 & Down & $8.18 \mathrm{E}-03$ \\
\hline 595 & CCND1 & -5.52 & Down & $1.14 \mathrm{E}-03$ \\
\hline
\end{tabular}


A

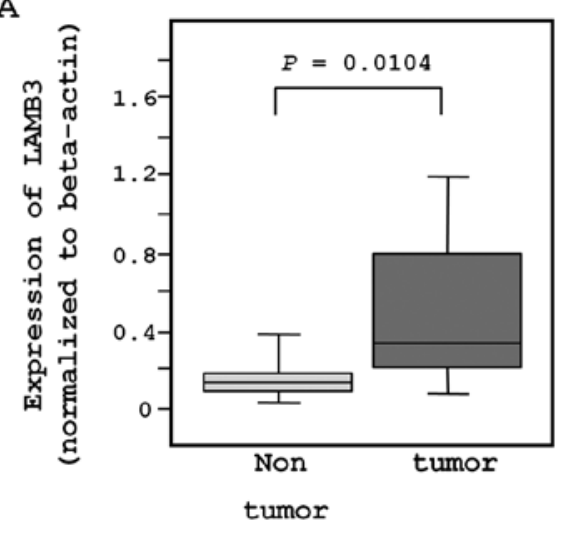

B

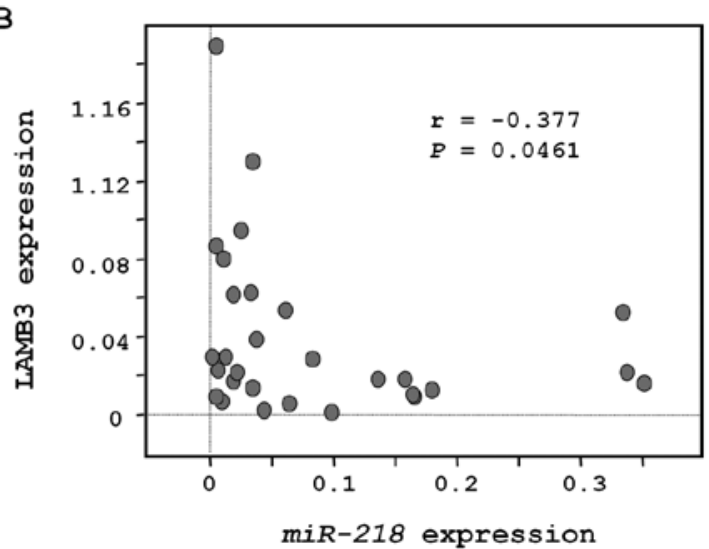

Figure 3. Expression of $L A M B 3$ in cervical-SCC clinical specimens. (A) Expression of $L A M B 3$ in cervical-SCC tissues and nontumor tissues as determined by qRT-PCR. ACTB was used as an internal control. (B) The correlation between the expression of $m i R-218$ and $L A M B 3$ was analyzed in cervical-SCC and non-tumor tissues.

A

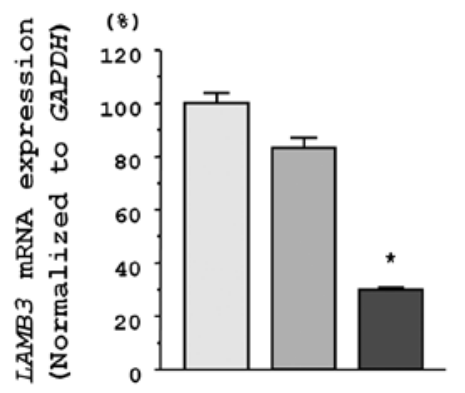

B

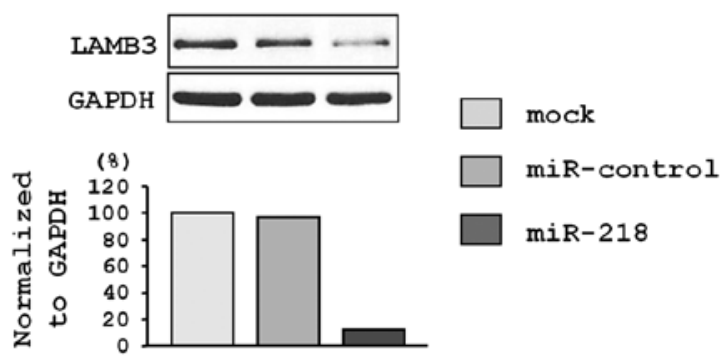

C
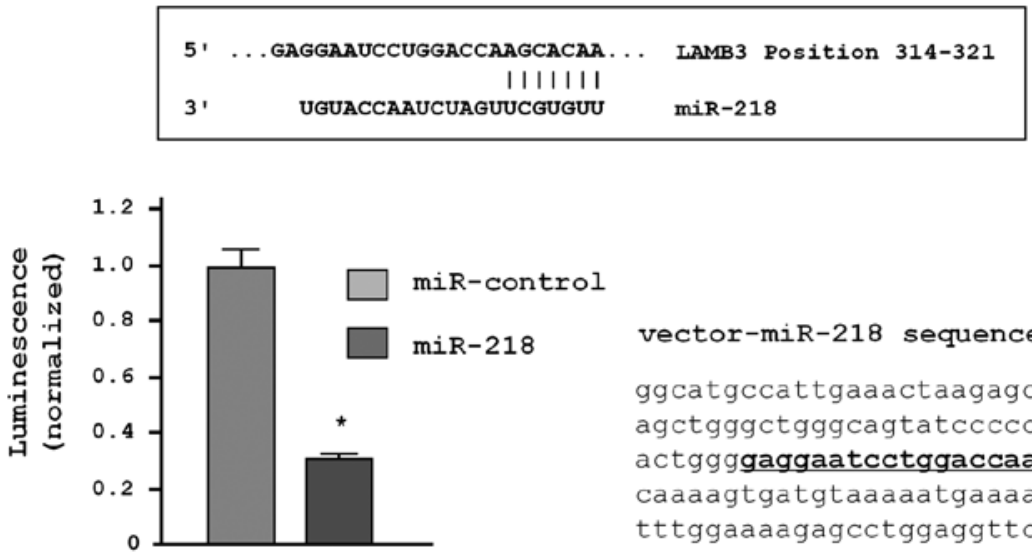

vector-miR-218 sequence

ggcatgccattgaaactaagagctctcaagtcaagga agctgggctgggcagtatcceccgcettagttctcc actggggaggaatcctggaccaagcacaaaacttaa caaagtgatgtaaaatgaaagccaataaaatc tttggaaagagcctggaggttc

Figure 4. $m i R-218$ directly regulates $L A M B 3$. (A) mRNA expression of $L A M B 3$ as measured by qRT-PCR $72 \mathrm{~h}$ after transfection with $10 \mathrm{nM} m i R-218$. GAPDH was used as an internal control. "P $\mathrm{P}<0.0001$. (B) Protein expression of LAMB3 as measured by western blot analysis $72 \mathrm{~h}$ after transfection with $10 \mathrm{nM} m i R-218$. GAPDH was used as a loading control. The expression ratio of LAMB3 was evaluated using ImageJ software. (C) A putative miR-218 binding site in the 3'UTR of LAMB3 mRNA was identified using the TargetScan database (Upper). Luciferase reporter assays were performed using a vector encoding the partial sequences of the $3^{\prime}$ UTR containing the putative $m i R$ - 218 target site. The vector $(10 \mathrm{ng})$ and $m i R$ - 218 or $m i R$-control $(10 \mathrm{nM})$ were cotransfected into CaSki cells. Renila luciferase activity was measured $24 \mathrm{~h}$ after transfection. The results normalized by firefly luciferase values are shown. ${ }^{*} \mathrm{P}<0.0001$.

Expression of LAMB3 in cervical SCC clinical specimens. The expression of $L A M B 3$ was significantly lower in clinical cervical $\mathrm{SCC}$ specimens $(\mathrm{n}=18 ; 0.053 \pm 0.049)$ than in non-cancerous specimens ( $\mathrm{n}=11 ; 0.017 \pm 0.014, \mathrm{P}=0.0104$; Fig. 3A). Moreover, $\angle A M B 3$ expression was significantly inversely correlated with miR-218 expression (r=-0.377; P=0.0461; Fig. 3B).
$L A M B 3$ is a direct target of $m i R-218$. We performed quantitative real-time RT-PCR and western blot analysis to investigate whether $L A M B 3$ mRNA and protein were downregulated by restoration of $m i R-218$. Importantly, both $L A M B 3 \mathrm{mRNA}$ and protein levels were significantly repressed in $m i R$-218-transfectants in comparison with mock transfectants (Fig. 4A and B). 
A

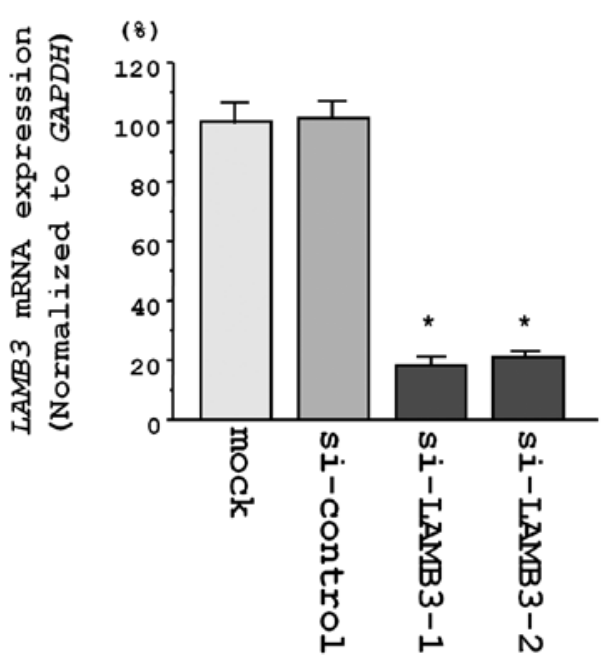

B

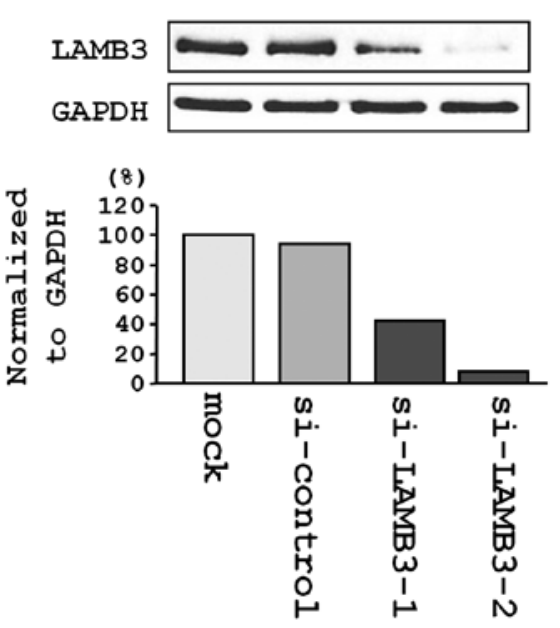

Figure 5. LAMB3 expression was suppressed by si-LAMB3 transfection at both the mRNA and protein levels in CaSKi cells. (A) mRNA expression of $L A M B 3$ as revealed by real-time qRT-PCR $72 \mathrm{~h}$ after transfection with $10 \mathrm{nM}$ si-LAMB3. ${ }^{*} \mathrm{P}<0.0001$. (B) Protein expression of LAMB3 as revealed by western blot analysis $72 \mathrm{~h}$ after transfection with $10 \mathrm{nM}$ si-LAMB3. GAPDH was used as a loading control. The expression ratio of LAMB3 was evaluated using ImageJ software.

A

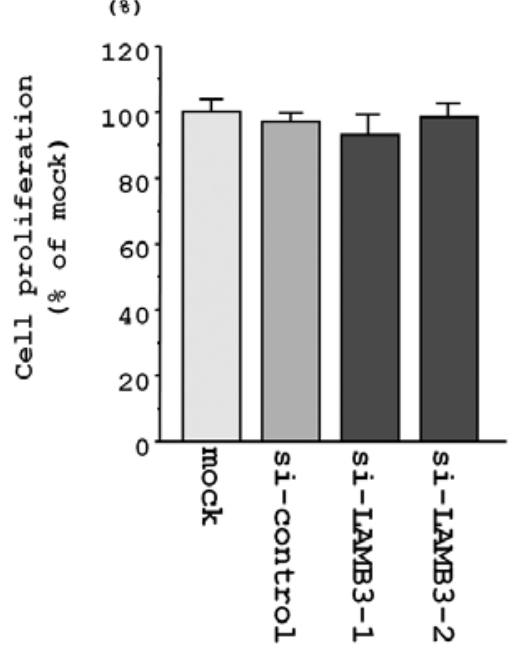

B

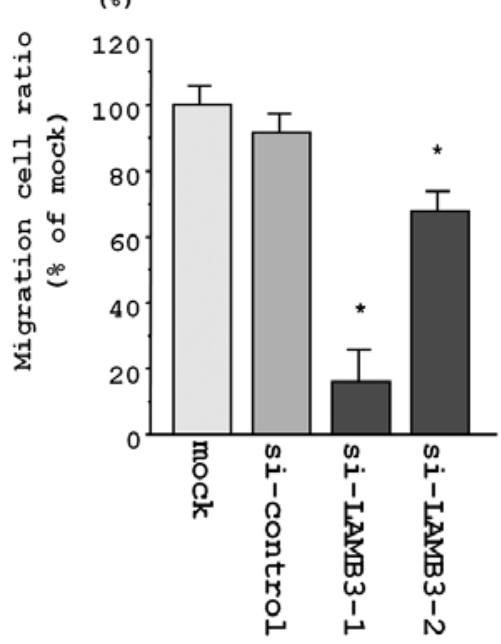

C

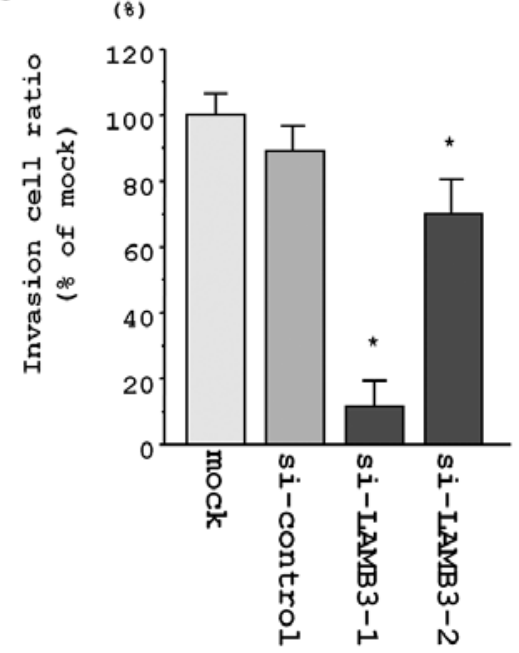

Figure 6. Effects of LAMB3 knockdown by si-LAMB3 transfection in CaSki cells. (A) Cell proliferation activities as revealed by XTT assay in the cervical-SCC cell line, CaSki. (B) Cell migration activities in CaSki cells. ${ }^{*} \mathrm{P}<0.0001$. (C) Cell invasion activities in CaSki cells. " $\mathrm{P}<0.0001$.

To determine whether the 3'UTR of LAMB3 had an actual target site for $m i R-218$, we performed a luciferase reporter assay by using a vector encoding the 3'UTR of LAMB3 mRNA. We found that the luminescence intensity was significantly reduced in $m i R-218$ transfectants as compared to mock and miRNA-control transfectants $(\mathrm{P}<0.0001$; Fig. $4 \mathrm{C})$.

Silencing of LAMB3 $m R N A$ and protein in a cervical SCC cell line. Next, we examined the impact of si- $L A M B 3$ transfection in CaSki cells. The expression of $L A M B 3$ mRNA was reduced in 2 si- $L A M B 3$ transfectants in comparison with mock and si-control transfectants $(\mathrm{P}<0.0001 ;$ Fig. $5 \mathrm{~A})$. Additionally, the expression of LAMB3 protein was reduced in si-LAMB3-1 and si-LAMB3-2 transfectants in comparison with mock and si-control transfectants $(\mathrm{P}<0.0001$ and $\mathrm{P}=0.0002$, respectively; Fig. 5B). These results showed that the 2 siRNAs were useful for loss-of-function assays in this study.

Effects of LAMB3 silencing on cell proliferation, migration and invasion in cervical SCC cell lines. To investigate the functional role of $L A M B 3$, we performed loss-of-function studies using si- $L A M B 3$ transfectants. The XTT assay revealed that cell proliferation was not inhibited in the 2 si-LAMB3 transfectants as compared with mock and si-control transfectants in CaSki cells $(82.4 \pm 10.7 \%, 100.2 \pm 6.1 \%, 100.0 \pm 14.6 \%$ and $95.6 \pm 11.2 \%$; $\mathrm{P}>0.0083$; Fig. 6A).

Additionally, the number of migrating cells was significantly decreased in both si-LAMB3 transfectants as compared with 
mock and si-control transfectants in CaSki cells $(10.6 \pm 2.7 \%$, $72.2 \pm 10.7 \%, 100.0 \pm 6.5 \%$ and $91.8 \pm 11.0 \%$, respectively; $\mathrm{P}<0.0001$; Fig. 6B).

The number of invading cells was also significantly decreased in si-LAMB3 transfectants as compared with mock and si-control transfectants in CaSki cells $(13.5 \pm 4.9 \%, 73.1 \pm 16.2 \%$, $100.0 \pm 13.7 \%$ and $88.4 \pm 18.0 \%$, respectively; $\mathrm{P}<0.0001$; Fig. $6 \mathrm{C}$ ).

\section{Discussion}

The discovery of non-coding RNA during the human genome sequencing project had a significant impact in cancer research (26). The reconstructing of genome-wide studies to include non-coding RNA is therefore necessary for cancer research. miRNAs are a class of small non-coding RNAs, and a growing body of evidence has suggested that miRNAs also contribute to cancer initiation, development and metastasis in many types of cancers, including cervical cancer (10).

It is believed that normal regulatory mechanisms can be disrupted by aberrant expression of tumor-suppressive or oncogenic miRNAs in cancer cells. Therefore, identification of aberrantly expressed miRNAs is the first step toward elucidating miRNA-mediated oncogenic pathways. Based on this, we identified the miRNA expression signatures in several human squamous cell carcinomas, including esophageal SCC, hypopharyngeal SCC, maxillary sinus SCC and lung SCC, allowing the elucidation of multiple tumor-suppressive miRNAs (12-15). Our previous studies showed that $m i R-218$ is a frequently downregulated miRNA and that restoration of this miRNA inhibited cancer cell migration and invasion in head and neck SCC (HNSCC) cells (19). We also searched for downregulated miRNAs in cervical SCC by examining expression signatures published in public databases (27-31). These data indicate that $m i R-218$ is frequently downregulated miRNA in cervical SCC. Thus, we focused on $m i R-218$ and investigated the functional significance of this miRNA in mediating cancer pathways.

In the human genome, $2 \mathrm{miR}-218$ precursor genes, $m i R-218-1$ and $m i R-218-2$, have identical sequences in the mature miRNA and map to human chromosomes 4 p15.31 and $6 \mathrm{q} 35.1$, respectively. Interestingly, the genomic regions of $m i R-218-1$ and $m i R-218-2$ are located in the introns of the SLIT2 and SLIT3 genes, respectively. Downregulation of $m i R-218$ in cancer cells has been shown to be caused by promoter hypermethylation of SLIT2 and SLIT3 genes (20). Silencing of $m i R-218$ by DNA hypermethylation has also been reported in oral SCC using a function-based screening approach (21). On the other hand, several reports have indicated that silencing of $m i R-218$ in cervical SCC was caused by HPV infection $(24,32)$. Our expression data showed that $m i R-218$ expression was significantly reduced in both HPV-positive cells (CaSki, HeLa and ME180) and HPV-negative cells (Yumoto), in addition to clinical specimens. Since the molecular mechanisms of $m i R-218$ silencing in cervical SCC are still unclear, further study is necessary to solve this problem.

In the current study, we found significant inhibition of cancer cell migration and invasion in cervical SCC cell lines (CaSki, HeLa, ME180 and Yumoto) by miR-218 restoration, suggesting that $m i R-218$ is a tumor-suppressive miRNA in cervical SCC. Our previous reports in HNSCC also showed that $m i R-218$ contributes to cancer cell migration and invasion (19). The tumor-suppressive function of $m i R-218$ has also been reported in several types of cancers, and $m i R-218$ has been shown to target several oncogenic genes, such as Rictor (oral cancer), survivin and ROBO1 receptor (nasopharyngeal cancer and gastric cancer) (20-22). Our recent report also indicated that restoration of $m i R-218$ inhibited cancer cell proliferation, migration, and invasion in bladder cancer $(23,33)$. These data suggested that $m i R-218$ is an important tumor-suppressive miRNA that is deeply involved in human cancers.

miRNAs are unique in their ability to regulate many protein-coding genes. Bioinformatic predictions have indicated that miRNAs regulate more than $30 \%$ of proteincoding genes (34). A single miRNA is capable of targeting a number of genes to globally regulate biological processes. The identification of novel cancer pathways and responsible genes regulated by tumor-suppressive $m i R-218$ in cervical SCC is the next step for our understanding of cervical SCC oncogenesis. Thus, we pursued GeneCodis analysis to reveal the functional significance of these genes potentially regulated by $m i R$ - 218 in cervical SCC. The GeneCodis analysis applies many genes to known pathways in the KEGG Pathway Database, and these data facilitate our understanding of tumorsuppressive miRNA-mediated molecular pathways in human cancer. This method of analysis has previously been used to efficiently identify tumor-suppressive miRNA-mediated cancer pathways in our laboratory (19). In the current study, the GeneCodis analysis revealed 105 signaling pathways, as highlighted in Table II. In these pathways, we focused on the focal adhesion pathway and the 48 genes contained within this pathway.

To search for genes regulated by tumor-suppressive $m i R-218$ in cervical SCC, we used gene expression profiling in this study (deposited in the GEO database as accession no. GSE6791). Among the 48 genes in the focal adhesion pathway, 10 were upregulated in cervical SCC clinical specimens, indicating that these genes were candidates for regulation by tumor-suppressive $m i R-218$ in cervical SCC. From these genes, we focused on $L A M B 3$, a component of laminin-332, and investigated the functional significance of this gene.

Laminin-332, a heterotrimer composed of 3 chains (LAMA3, LAMB3 and LAMC2), is an adhesion substrate for epithelial cells and regulates epithelial cell migration during epithelial regeneration and repair processes $(35,36)$. Several immunohistochemical studies have shown that laminin-332 or its subunit LAMC2 is expressed in tumor cells at the invasion front or in budding tumor cells in many types of human cancers, such as adenocarcinomas of the colon, breast, pancreas and lung, SCC of the esophagus and melanoma (35). Our data demonstrated that $L A M B 3$ was directly regulated by $m i R-218$ and functioned as an oncogene, contributing to cancer cell migration and invasion in cervical SCC. Many studies have indicated that laminin-332 binds to several cell-surface receptors, such as integrins, epidermal growth factor receptor and syndecan-1 (37-39). Among these binding partners, integrins are cell surface transmembrane proteins that mediate extracellular signals and intracellular pathways, 
leading to control of the cell cycle, cell migration, and invasion in cancer cells (40). It will be necessary to analyze the signal pathways associated with the interactions of integrins and laminin-332 in cervical SCC in the future.

\section{Acknowledgements}

This study was supported by KAKENHI (C), 24592590.

\section{References}

1. Jemal A, Bray F, Center MM, Ferlay J, Ward E and Forman D: Global cancer statistics. CA Cancer J Clin 61: 69-90, 2011.

2. Walboomers JM, Jacobs MV, Manos MM, et al: Human papillomavirus is a necessary cause of invasive cervical cancer worldwide. J Pathol 189: 12-19, 1999.

3. Muñoz N, Bosch FX, De Sanjosé S, et al: Epidemiologic classification of human papillomavirus types associated with cervical cancer. N Engl J Med 348: 518-527, 2003.

4. Clifford GM, Smith JS, Plummer M, Muñoz N and Franceschi S: Human papillomavirus types in invasive cervical cancer worldwide: a meta-analysis. Br J Cancer 88: 63-73, 2003.

5. Band V, Dalal S, Delmolino L and Androphy EJ: Enhanced degradation of p53 protein in HPV-6 and BPV-1 E6-immortalized human mammary epithelial cells. EMBO J 12: 1847-1852, 1993.

6. Lechnerl MS, Mackl DH, Finicle AB, Crook T, Vousden KH and Laiminsl LA: Human papillomavirus E6 proteins bind p53 in vivo and abrogate $\mathrm{p} 53$-mediated repression of transcription. EMBO J 11: 3045-3052, 1992.

7. Thomas M, Pim D and Banks L: The role of the E6-p53 interaction in the molecular pathogenesis of HPV. Oncogene 18 7690-7700, 1999.

8. Münger K and Howley PM: Human papillomavirus immortalization and transformation functions. Virus Res 89: 213-228, 2002.

9. Filipowicz W, Bhattacharyya SN and Sonenberg N: Mechanisms of post-transcriptional regulation by microRNAs: are the answers in sight? Nat Rev Genet 9: 102-114, 2008.

10. Nelson KM and WEiss GJ: MicroRNAs and cancer: past, present, and potential future. Mol Cancer Ther 7: 3655-3660, 2008.

11. Esquela-Kerscher A and Slack FJ: Oncomirs - microRNAs with a role in cancer. Nat Rev Cancer 6: 259-269, 2006.

12. Kikkawa N, Hanazawa T, Fujimura L, et al: miR-489 is a tumour-suppressive miRNA target PTPN11 in hypopharyngeal squamous cell carcinoma (HSCC). Br J Cancer 103: 877-884, 2010.

13. Nohata N, Hanazawa T, Kikkawa N, et al: Tumour suppressive microRNA-874 regulates novel cancer networks in maxillary sinus squamous cell carcinoma. Br J Cancer 105: 833-841, 2011.

14. Kano M, Seki N, Kikkawa N, et al: miR-145, miR-133a and miR-133b: tumor-suppressive miRNAs target FSCN1 in esophageal squamous cell carcinoma. Int J Cancer 127: 2804-2814, 2010.

15. Moriya $\mathrm{Y}$, Nohata N, Kinoshita $\mathrm{T}$, et al: Tumor suppressive microRNA-133a regulates novel molecular networks in lung squamous cell carcinoma. J Hum Genet 57: 38-45, 2012.

16. Hidaka H, Seki N, Yoshino H, Yamasaki T, et al: Tumor suppressive microRNA-1285 regulates novel molecular targets: aberrant expression and functional significance in renal cell carcinoma. Oncotarget 3: 44-57, 2012.

17. Ichimi T, Enokida H, Okuno Y, et al: Identification of novel microRNA targets based on microRNA signatures in bladder cancer. Int J Cancer 125: 345-352, 2009.

18. Yoshino H, Chiyomaru T, Enokida H, et al: The tumoursuppressive function of miR-1 and miR-133a targeting TAGLN2 in bladder cancer. Br J Cancer 104: 808-818, 2011.
19. Kinoshita T, Hanazawa T, Nohata N, et al: Tumor suppressive microRNA-218 inhibits cancer cell migration and invasion through targeting laminin-332 in head and neck squamous cell carcinoma. Oncotarget 3: 1386-1400, 2012

20. Alajez NM, Lenarduzzi M, Ito E, et al: MiR-218 suppresses nasopharyngeal cancer progression through downregulation of survivin and the SLIT2-ROBO1 pathway. Cancer Res 71: 2381-2391, 2011

21. Uesugi A, Kozaki K-I, Tsuruta T, et al: The tumor suppressive microRNA miR-218 targets the mTOR component Rictor and inhibits AKT phosphorylation in oral cancer. Cancer Res 71: 5765-5678, 2011.

22. Tie J, Pan Y, Zhao L, et al: MiR-218 inhibits invasion and metastasis of gastric cancer by targeting the Robol receptor. PLoS Genet 6: e1000879, 2010.

23. Tatarano S, Chiyomaru T, Kawakami K, et al: miR-218 on the genomic loss region of chromosome 4 p15.31 functions as a tumor suppressor in bladder cancer. Int J Oncol 39: 13-21, 2011.

24. Martinez I, Gardiner AS, Board KF, Monzon FA, Edwards RP and Khan SA: Human papillomavirus type 16 reduces the expression of microRNA-218 in cervical carcinoma cells. Oncogene 27: 2575-2582, 2008

25. Gravitt PE, Peyton CL, Alessi TQ, et al: Improved amplification of genital human papillomaviruses. J Clin Microbiol 38: 357-361, 2000.

26. Mattick JS: RNA regulation: a new genetics? Nat Rev Genet 5: 316-323, 2004

27. Lee J-W, Choi CH, Choi J-J, et al: Altered MicroRNA expression in cervical carcinomas. Clin Cancer Res 14: 2535-2542, 2008.

28. Wang X, Tang S, Le S-Y, et al: Aberrant expression of oncogenic and tumor-suppressive microRNAs in cervical cancer is required for cancer cell growth. PLoS One 3: e2557, 2008

29. Pereira PM, Marques JP, Soares AR, Carreto L and Santos MAS: MicroRNA expression variability in human cervical tissues. PLoS One 5: el1780, 2010.

30. Li Y, Wang F, Xu J, et al: Progressive miRNA expression profiles in cervical carcinogenesis and identification of HPV-related target genes for miR-29. J Pathol 224: 484-495, 2011

31. Rao Q, Zhou H, Peng Y, Li J and Lin Z: Aberrant microRNA expression in human cervical carcinomas. Med Oncol 29: 1242-1248, 2012

32. Li Y, Liu J, Yuan C, Cui B, Zou X and Qiao Y: High-risk human papillomavirus reduces the expression of microRNA-218 in women with cervical intraepithelial neoplasia. J Int Med Res 38: 1730-1736, 2010

33. Chiyomaru T, Enokida H, Kawakami K, et al: Functional role of LASP1 in cell viability and its regulation by microRNAs in bladder cancer. Urologic Oncol 30: 434-443, 2012.

34. Bartel DP, Lee R and Feinbaum R: MicroRNAs: Genomics, biogenesis, mechanism, and function. Cell 116: 281-297, 2004.

35. Guess CM and Quaranta V: Defining the role of laminin-332 in carcinoma. Matrix Biol 28: 445-455, 2009.

36. Marinkovich MP: Laminin 332 in squamous-cell carcinoma. Nat Rev Cancer 7: 370-380, 2007.

37. Carter WG, Ryan MC and Gahr PJ: Epiligrin, a new cell adhesion ligand for integrin $\alpha 3 \beta 1$ in epithelial basement membranes. Cell 65: 599-610, 1991.

38. Schenk S, Hintermann E, Bilban M, et al: Binding to EGF receptor of a laminin-5 EGF-like fragment liberated during MMP-dependent mammary gland involution. J Cell Biol 161: 197-209, 2003

39. Okamoto O, Bachy S, Odenthal U, et al: Normal human keratinocytes bind to the alpha3LG4/5 domain of unprocessed laminin-5 through the receptor syndecan-1. J Biol Chem 278: 44168-44177, 2003.

40. Mizejewski GJ: Role of integrins in cancer: survey of expression patterns. Proc Soc Exp Biol Med 222: 124-138, 1999. 